\title{
4D-Dynamic Contrast-Enhanced MRI for Preoperative Localization in Patients with Primary Hyperparathyroidism
}

\author{
(D).L. Becker, (D) V. Patel, (D).J. Johnson, (D) M. Guerrero, (D).R. Klein, (D) G.F. Ranvier, (DR.P. Owen, (D). Pawha, and (D). Nael
}

\begin{abstract}
BACKGROUND AND PURPOSE: Our aim was to test the hypothesis that our recently introduced 4D-dynamic contrast-enhanced MR imaging with high spatial and temporal resolution has equivalent accuracy to 4D-CT for preoperative gland localization in primary hyperparathyroidism without requiring exposure to ionizing radiation.
\end{abstract}

MATERIALS AND METHODS: Inclusion criteria were the following: 1) confirmed biochemical diagnosis of primary hyperparathyroidism, 2) preoperative 4D-dynamic contrast-enhanced MR imaging, and 3) surgical cure with $>50 \%$ decrease in serum parathyroid hormone intraoperatively. 4D-dynamic contrast-enhanced studies were reviewed independently by 2 neuroradiologists to identify the side, quadrant, and number of abnormal glands, and compared with surgical and pathologic results.

RESULTS: Fifty-four patients met the inclusion criteria: 37 had single-gland disease, and 17, multigland disease ( 9 with double-gland hyperplasia; 3 with 3-gland hyperplasia; and 5 with 4-gland hyperplasia). Interobserver agreement $(\kappa)$ for the side (right versus left) was 0.92 for single-gland disease and 0.70 for multigland disease. Interobserver agreement for the quadrant (superior versus inferior) was 0.70 for single-gland disease and 0.69 for multigland disease. For single-gland disease, the gland was correctly located in $34 / 37$ (92\%) patients, with correct identification of the side in $37 / 37(100 \%)$ and the quadrant in $34 / 37$ (92\%) patients. For multigland disease, the glands were correctly located in 35/47 (74\%) patients, with correct identification of the side in $35 / 47(74 \%)$ and the quadrant in 36/47 (77\%).

CONCLUSIONS: The proposed high spatial and temporal resolution 4D-dynamic contrast-enhanced MR imaging provides excellent diagnostic performance for preoperative localization in primary hyperparathyroidism, with correct gland localization of $92 \%$ for single-gland disease and $74 \%$ in multigland disease, superior to $4 \mathrm{D}-\mathrm{CT}$ studies.

ABBREVIATIONS: CAIPIRINHA = controlled aliasing in parallel imaging results in higher acceleration; DCE $=$ dynamic contrast-enhanced; MGD $=$ multigland disease; PHPT = primary hyperparathyroidism; PTA = single parathyroid adenoma; PTH = parathyroid hormone; SGD = single-gland disease; TRICKS = timeresolved imaging of contrast kinetics; TWIST $=$ time-resolved imaging with stochastic trajectories

$\mathbf{P}$ rimary hyperthyroidism (PHPT) causes overproduction of the parathyroid hormone (PTH) leading to hypercalcemia and is the most common parathyroid disease. It is caused by single parathyroid adenoma (PTA) in $80 \%-90 \%,{ }^{1}$ multigland disease (MGD) in 5\%-15\%, and carcinoma in $<1 \%{ }^{2}$ MGD glands are usually smaller than in adenoma and hyperplasia and can

Received November 2, 2018; accepted after revision January 1, 2020.

From the Departments of Medical Imaging (J.L.B., V.P., K.J.J.), Surgery (M.G.), and Pathology (R.R.K.), University of Arizona, Tucson, Arizona; Departments of Surgery (G.F.R., R.P.O.), and Radiology (P.P., K.N.), Icahn School of Medicine at Mount Sinai, New York, New York; and Department of Radiological Sciences (K.N.), David Geffen School of Medicine at University of California, Los Angeles, Los Angeles, California.

Please address correspondence to Jennifer Becker, BMBS, FRCR, Department of Medical Imaging, University of Arizona, 1501 North Campbell Ave, Tucson, AZ, 85724; e-mail: jbecker@radiology.arizona.edu

http://dx.doi.org/10.3174/ajnr.A6482 asymmetrically involve any number or all of the 4 parathyroid glands. ${ }^{3}$ Accurate preoperative localization of abnormal parathyroid tissue is essential for guiding curative, focused unilateral neck exploration for SGD and is particularly crucial for re-operative parathyroidectomy surgery, which currently has a failure rate $4 \times$ that of primary surgery. ${ }^{4}$ Other advantages include smaller scars, shorter operations, reduced complication rates, and lower surgical cost. ${ }^{5-9}$

4D-CT has gained wide acceptance for presurgical PHPT planning, with multiphase imaging having superior diagnostic performance compared with both sonography and technetium (Tc99m) sestamibi scintigraphy. ${ }^{10-12} 4 \mathrm{D}-\mathrm{CT}$ is, however, associated with high radiation doses of 5.56-10.4 mSv, depending on the number of phases scanned. ${ }^{13-15}$ It can have radiation doses to the thyroid gland of up to $57 \times$ that of Tc99m scintigraphy $(92.0$ versus $1.6 \mathrm{mGy}){ }^{15}$ Radiation exposure is the main risk for 
development of thyroid cancer, with increased risk to younger patients and with thyroid doses of 50-100 mGy. ${ }^{16}$ Thus, judicious use of $4 \mathrm{D}-\mathrm{CT}$ has recently been recommended. ${ }^{13}$ Dual-phase CT has been suggested as an alternative to 3- or 4-phase imaging and is associated with lower radiation doses, but at a cost of reduced accuracy for localizing PTAs to the correct side (79\%-81\%) and quadrant $(55 \%-76 \%){ }^{17-20}$

$4 \mathrm{D}$-dynamic contrast-enhanced (DCE) MR imaging is, therefore, a very attractive alternative to $4 \mathrm{D}-\mathrm{CT}$. Like $4 \mathrm{D}-\mathrm{CT}$, it exploits the hypervascular nature of abnormal parathyroid lesions, but without the risk to the patient arising from radiation exposure. ${ }^{21}$ Until recently, the competing requirements for high spatial and high temporal resolution imaging over a large FOV prohibited a true $4 \mathrm{D}$ application for MR imaging. ${ }^{21,22}$

This study tests the hypothesis that our recently introduced 4D-DCE MR imaging has diagnostic accuracy equivalent to that of $4 \mathrm{D}$-CT for preoperative localization of abnormal parathyroid glands in patients with PHPT, without the need for ionizing radiation.

\section{MATERIALS AND METHODS}

\section{Patients}

This Health Insurance Portability and Accountability Act-compliant prospective study was performed under the approval of the institutional review board at the University of Arizona and Icahn School of Medicine. Consecutive new patients with PHPT presenting to 2 surgeons from December 2013 to December 2015 were eligible for the study. Inclusion criteria were the following: 1) no previous neck surgery, 2) PHPT confirmed with biochemical confirmation of elevated serum PTH and calcium levels, 3) MR imaging consent with no MR imaging contraindication, 4) preoperative $4 \mathrm{D}$-DCE MR imaging of the neck, and 5) surgical cure guided by MR imaging and confirmed by $>50 \%$ reduction of serum PTH.

\section{Image Acquisition}

MR imaging was performed using a 3T Magnetom Skyra MR imaging system (Siemens, Erlangen, Germany) with the patient breathing freely. A combination 20-element head and neck coil was used for radiofrequency signal reception. 4D-DCE MR imaging was performed using a $3 \mathrm{D}$ volumetric interpolated examination sequence using the following parameters: $\mathrm{TR}=$ $4.06 \mathrm{~ms}$, dual-echo for Dixon fat suppression (first $\mathrm{TE}=$ $1.31 \mathrm{~ms}$, second $\mathrm{TE}=2.54 \mathrm{~ms}$ ), flip angle $=9^{\circ}$, matrix $=160 \mathrm{~mm}$, FOV $=200 \mathrm{~mm}, 60$ sections $\times 2 \mathrm{~mm}$ thick.

Time-resolved imaging with stochastic trajectories (TWIST) ${ }^{23}$ with a sampling density of $33 \%$ and controlled aliasing in parallel imaging results in higher acceleration (CAIPIRINHA) ${ }^{24}$ with an acceleration factor of 4 were incorporated, resulting in a net acceleration of 8 , which was used to acquire a $3 \mathrm{D}$ dataset with a voxel size of $1.3 \times 1.3 \times 2.3 \mathrm{~mm}^{3}$ and a temporal resolution of 6 seconds over a craniocaudal coverage of $120 \mathrm{~mm}$, spanning the inferior mandibular rim to the carina. Twenty-four temporal frames were obtained during 144 seconds of acquisition time after intravenous injection of $0.1 \mathrm{mmol} / \mathrm{kg}$ of MultiHance (gadobenate dimeglumine, $529 \mathrm{mg} / \mathrm{mL}$; Bracco Diagnostics, Princeton, New Jersey) at $4 \mathrm{~mL} / \mathrm{s}$ followed by $20 \mathrm{~mL}$ of saline at $4 \mathrm{~mL} / \mathrm{s}$.

\section{Image Analysis}

The 4D-DCE MR imaging datasets were independently analyzed by 2 neuroradiologists blinded to the patient's previous imaging and clinical, surgical, and pathologic data. The $4 \mathrm{D}-\mathrm{MR}$ imaging studies were analyzed systematically on our PACS. Abnormal parathyroid glands were identified as arterial enhancing nodules that demonstrated early increased signal intensity at the same time as or within 1-2 frames (up to 12 seconds) of the onset of carotid enhancement, with maximal signal intensity and enhancement during the early venous phase and decreased signal intensity due to contrast washout in the later venous phase. ${ }^{10}$

Readers searched the most common locations of the parathyroid glands (native) as well as all possible ectopic locations. ${ }^{15}$ Discrepancies between readers were resolved by consensus and used for assessment of diagnostic accuracy in comparison with surgical and pathologic findings. For each gland, the side was recorded in relation to the midline, and the quadrant was recorded as superior or inferior, depending on the relation to the midpole of the thyroid gland.

Parathyroid volumes were calculated using the ellipsoid formula [(4/3)axbxc], where a represent the maximum short axis diameter, $\mathrm{b}$ the maximum long axis diameter and $\mathrm{c}$ the maximum diameter of the gland in the coronal plane.

\section{Surgical Confirmation}

All patients underwent surgical resection with the side, quadrant, and size of the resected parathyroid glands recorded. The position of the gland was recorded in relation to the recurrent laryngeal nerve. The origin of the arterial supply to the abnormal gland overrode anatomic location if discrepant in determining the gland location as superior or inferior. All patients included in the study had surgical cure. This was confirmed by a decrease in the intraoperative serum parathyroid hormone level of at $>50 \% 10$ minutes following resection compared with the intraoperative pre-excision level. The pathologist measured the weight and dimensions of the excised glands, and their volume was calculated with the same ellipsoid formula used for the imaging volume.

\section{Statistical Analysis}

Statistical analysis was performed using MedCalc for Windows (Version 12.2.1; MedCalc Software, Mariakerke, Belgium). Clinical and lesion characteristics were compared between subjects with SGD and MGD using univariate analysis, with the Fisher exact test for categoric variables and the unpaired 2-tailed $t$ test for continuous variables.

Interobserver agreement was tested using a linear weighted $\kappa$ test. By means of consensus reads, the ratios of correctly identified lesion sides and quadrants were calculated against the final lesion assignment, and the percentages (sensitivities) were calculated for SGD and MGD. The significance level was defined as $P<.05$.

\section{RESULTS}

A total of 54 patients met our inclusion criteria. All patients had parathyroid glands identified. Thirty-seven patients had a single adenoma (Fig 1), and 17 patients had MGD with a total of 47 


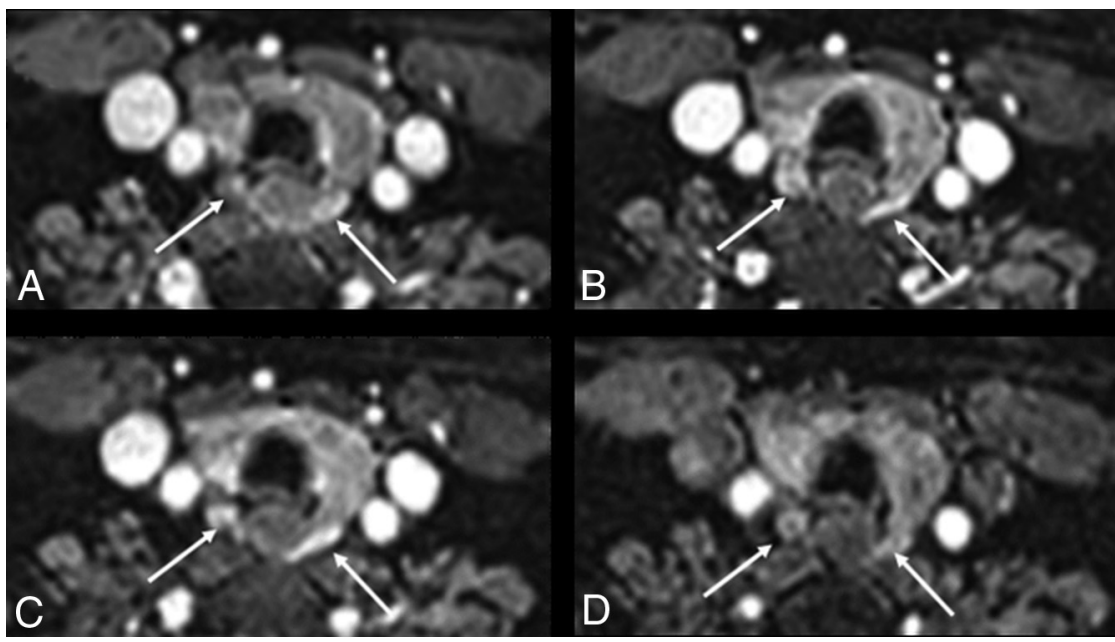

FIG 1. A 39-year-old woman with PHPT and MGD with bilateral glands imaged in the lower quadrants. A, Axial early arterial phase. $B$, Early venous phase. $C$, Midvenous phase. $D$, Later venous phase. The contour of the glands is different in $A$ and $B$ due to interval patient motion without image degradation. Images show bilateral MGD glands (white arrows) with early arterial enhancement and increased signal intensity compared with the adjacent thyroid gland (A). Signal intensity increases into the early venous phase, with MGD glands having signal intensity similar to that of the carotid artery on the early venous phase and increased signal compared with the thyroid gland $(B)$. At the mid-venous phase, the MGD glands have decreased signal intensity compared with the carotid artery due to early washout but still have increased signal compared with the thyroid gland $(C)$. The MGD gland signal decreases further in the later venous phase, becoming isointense with the thyroid gland $(D)$.
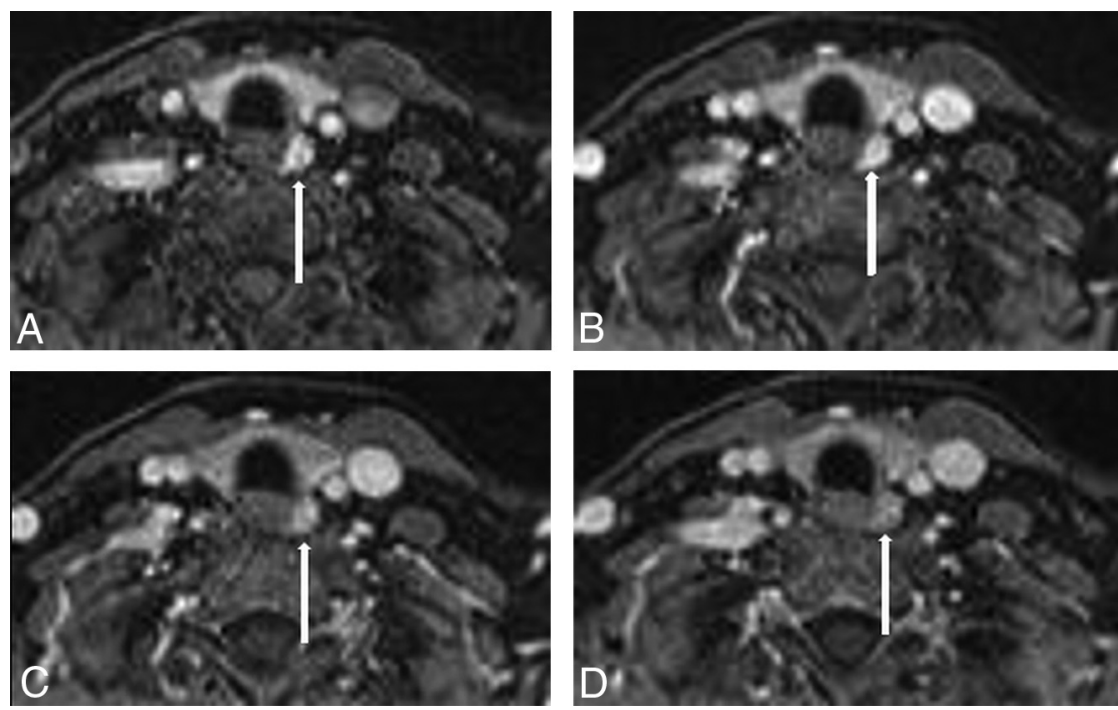

FIG 2. A 54-year-old woman with PHPT and SGD in the left lower quadrant. A, Axial early arterial phase. $B$, Early venous phase. $C$, Midvenous phase. $D$, Later venous phase. Images show a left lower quadrant parathyroid adenoma (white arrow) with early arterial enhancement $(A)$, increasing with signal intensity similar to that of the internal carotid artery $(B)$, with mildly decreased signal intensity compared with the carotid artery due to early venous washout (C), and decreased signal intensity compared with the adjacent internal carotid artery and jugular vein in the later venous phase $(D)$.

hyperplastic glands (Fig 2): 9 with double-gland hyperplasia, 3 with asymmetric 3-gland hyperplasia, and 5 with 4-gland hyperplasia. Demographic data and basic clinical information for the entire cohort, subdivided between patients with SGD versus
MGD, are provided in Table 1 . There were 3 ectopic glands: 1 within the thyroid gland and 2 in the superior mediastinum, all correctly identified as inferior glands. All other glands were posterior to the thyroid gland or related to the tracheal esophageal groove. There was no statistically difference in age, sex, preoperative serum PTH levels, and calcium levels between SGD and MGD (Table 1). The size and volume of the resected abnormal parathyroid glands were significantly smaller in patients with MGD (Table 1).

\section{Surgical Findings}

Intraoperative findings and operative reports were reviewed in conjunction with 4D-DCE MR imaging in a joint meeting between a neuroradiologist and surgeon. The surgical location of parathyroid lesions for each gland was determined as superior versus inferior and right versus left and was used as the reference standard to determine the accuracy of MR imaging reads. For the SGD, the location and side of 37 resected glands were recorded as left $(n=20,54 \%)$, right ( $n=17,46 \%)$, superior $(n=26$, $70 \%)$, and inferior $(n=11,30 \%)$. For the 47 MGD glands, the side and location of each gland were recorded as left $(n=27,57 \%)$, right $(n=20$, $43 \%)$, superior ( $n=27,57 \%)$, and inferior $(n=20,42 \%)$. All ectopic glands were inferior. Resection was recorded as 2, 3, or 3.5 glands and was recorded as 3.5 glands if any of the fourth gland was resected.

\section{D-DCE MR Imaging in SGD}

A total of $36 / 37$ (97\%) glands were correctly localized to the right or left by both readers, resulting in an interobserver agreement of $\kappa=0.92$ (95\% CI, 0.80-1.0). One observer incorrectly identified $1 / 20$ (5\%) glands as right-sided, resolved by consensus, resulting in $100 \%$ sensitivity for correct side identification.

For determination of quadrant (superior versus inferior), readers 1 and 2 correctly identified 34/37 (92\%) and 30/37 (81\%) glands, respectively, resulting in an interobserver agreement of $\kappa=0.70$ (95\% CI, 0.45$0.920)$. Three glands were identified as superior by reader 1 and inferior by reader 2; 2 glands, as inferior by reader 1 and superior by 
Table 1: Baseline and clinical data in patients with single adenoma and multiglandular disease (univariate analysis)

\begin{tabular}{lcccc}
\hline \multicolumn{1}{c}{ Variable } & Total (54) & SGD $(\boldsymbol{n}=37)$ & MGD $(\boldsymbol{n}=17)$ & $\boldsymbol{P}$ Value \\
\hline Age (mean) (SD) (yr) & $58.6(13.2)$ & $59.1(12.0)$ & $57.4(15.5)$ & .66 \\
Sex (M/F) & $(14 / 40)$ & $(10 / 27)$ & $(4 / 13)$ & .70 \\
Preoperative PTH (mean) (SD) & $131.6(62.6)$ & $134.2(63.2)$ & $148.8(109.2)$ & .56 \\
Preoperative calcium (mean) (SD) & $10.8(0.6)$ & $10.8(0.7)$ & $10.7(0.47)$ & .47 \\
Volume (cm $\left.{ }^{3}\right)($ mean) (SD) & $4.25(6.51)$ & $4.38(1.09)$ & $1.01(2.24)$ & .02 \\
Weight (mean) (SD) (g) & $0.60(0.51)$ & $0.95(0.60)$ & $0.34(0.26)$ & .001 \\
\hline
\end{tabular}

identified in $2 / 9(22 \%)$. Of the 3 patients with 3 glands removed, $1 / 3$ (33\%) had all glands correctly localized, with 1 gland not identified in $1 /$ $3(33 \%)$ and incorrectly localized in $1 / 3(33 \%)$. Of the 5 patients with 3.5 glands removed, only $1 / 5$ (20\%) had all glands correctly localized, 1 of 5 (20\%) had 1 gland not identified, $1 / 5$ (20\%) had 1 gland not identified and

Table 2: MGD-results for identification of side and quadrant of glands

\begin{tabular}{lccc}
\hline & \multicolumn{3}{c}{ No. of Glands (Total, 47) } \\
\cline { 2 - 4 } & Reader 1 & Reader 2 & Consensus \\
\hline Side (right or left) & & & \\
Total correctly localized & $35(74 \%)$ & $33(70 \%)$ & $35(74 \%)$ \\
Total incorrectly localized & $2(4 \%)$ & $1(2 \%)$ & $2(4 \%)$ \\
Total not identified at all & $10(21 \%)$ & $13(28 \%)$ & $10(21 \%)$ \\
Quadrant (superior or & & & \\
inferior) & & & \\
Total correctly localized & $33(70 \%)$ & $32(68 \%)$ & $36(77 \%)$ \\
Total incorrectly localized & $3(6 \%)$ & $2(4 \%)$ & $2(4 \%)$ \\
Total not identified at all & $11(23 \%)$ & $13(28 \%)$ & $9(19 \%)$ \\
\hline
\end{tabular}

reader 2. Following consensus reads, glands were correctly localized in 34/37 (92\%) patients and incorrectly identified in 3/37 (8\%) patients. No patient with SGD was mistakenly identified as having MGD.

\section{D-DCE MR Imaging in MGD}

A total of 35/47 (74\%) and 33/47 (70\%) removed MGD glands were correctly localized for side by readers 1 and 2, respectively, resulting in interobserver agreement of $\kappa=0.70$ (95\% CI, 0.51$0.86)$. More glands were not identified at all by both readers than were incorrectly localized. Ten of 47 (21\%) and 13/47 (28\%) glands were not identified by readers 1 and 2, respectively, with 2/47 (4\%) and 1/47 (2\%) glands incorrectly localized for side. Seven of the 10 glands (70\%) not identified by reader 1 and 9 of the 13 glands $(69 \%)$ not identified by reader 2 were in patients who had 3.5 glands removed. Consensus reads showed an overall sensitivity for side of $74 \%$ (35/47), with the side of disease correctly identified in $14 / 17$ (82\%) patients. Only $2 / 17$ patients (12\%) required bilateral neck dissection for unidentified single glands, contralateral to correctly identified single $(1 / 17,6 \%)$ and double $(1 / 17,6 \%)$ glands. In addition, 1 patient with 2 removed ipsilateral glands (6\%) was incorrectly identified with SGD.

For determination of the quadrant (superior versus inferior), readers 1 and 2 correctly identified 33/47 (70\%) and 32/ 47 (68\%) glands, respectively, resulting an interobserver agreement of $\kappa=0.69$ (95\% CI, 0.52-0.87). The quadrants were not identified at all for $11 / 47(23 \%)$ and $13 / 47$ (28\%) glands by readers 1 and 2, respectively. Two of 47 (4\%) glands were incorrectly localized by both readers. Consensus reads showed an overall sensitivity of $77 \%$ (36/47) for identification of the gland quadrant in MGD and incorrect localization of 2 (4\%) glands with 9 (19\%) glands not identified at all. Consensus reads showed the quadrant of disease correctly identified in 9/ $17(53 \%)$ patients. Seven of $9(78 \%)$ patients with 2 glands removed had both glands correctly localized, with 1 gland not
1 incorrectly localized, and 2/5 (40\%) had 1 gland not recognized (Tables 2 and 3).

\section{DISCUSSION}

This study proves that the described 4D-DCE MR imaging is highly accurate for preoperative localization of abnormal parathyroid glands in patients with PHPT. The image interpretation is straightforward without the need for off-line postprocessing and takes $>10$ minutes with high interobserver agreement for correct identification of the side and quadrant.

For SGD, our 4D-DCE MR imaging has a sensitivity of $100 \%$ for side and $92 \%$ for quadrant. This compares very favorably with $4 \mathrm{D}-\mathrm{CT}$, with its sensitivity of $73 \%-97 \%$ for side and $55 \%-88 \%$ for quadrant. ${ }^{4,10,11,19,20,25,26}$ No patient with SGD required bilateral neck surgery. Accurate identification of the side of the gland within the neck can be as important to the surgeon as identification of the quadrant. Identification of the quadrant may simply give a starting point for the operation with ipsilateral extension of a search being less invasive than a bilateral dissection. For MGD, we showed an overall sensitivity of $74 \%$ for the side and $77 \%$ for the quadrant, superior to $4 \mathrm{D}-\mathrm{CT}$ studies with a reported sensitivity of $29 \%-42.9 \% .{ }^{27,28}$ Only $12 \%$ of our patients with MGD required bilateral neck dissection for unidentified contralateral disease.

Our results compare favorably with those of nondynamic conventional MR imaging with a sensitivity for detection of SGD and MGD of 57\%-91\%, ${ }^{29-35}$ often using small study populations and selected patients, with many having MGD glands larger than those in our study. Like MR imaging and 4D-CT, our 4D-DCE MR imaging was more successful in detecting the larger SGD glands, with mean volume of $4.38 \mathrm{~cm}^{3}$, than the smaller MGD went unrecognized and unrecorded than were incorrectly localized. Satisfaction of search when looking for multiple small glands most likely accounts for this finding, with the number of unrecorded glands increasing with increasing numbers of glands removed, with the highest with 4 removed glands.

A number of investigators have used DCE MR imaging for preoperative localization of parathyroid adenomas with mixed results. Merchavy et $\mathrm{al}^{22}$ used a $4 \mathrm{D}-\mathrm{DCE} \mathrm{T} 1$ volumetric interpolated brain examination sequence at $1.5 \mathrm{~T}$ with precontrast images and postcontrast images at 13-second intervals for 10 timeframes to identify 7/7 (100\%) selected PTAs. The size of these glands was not reported, but PTA detection using ultrasound and sestamibi (MIBI) in this study was $90 \%$; higher than reported in other studies. $^{22}$

AJNR Am J Neuroradiol 41:522-28 Mar 2020 www.ajnr.org glands, with mean volume of $1.01 \mathrm{~cm} .{ }^{3,29}$ For MGD, more glands 
Table 3: SGD and MGD-patient results for identification of side and quadrant of glands

No. of Patients (Total, 17)

\begin{tabular}{|c|c|c|}
\hline \multicolumn{3}{|l|}{ Side (right or left) } \\
\hline Total with all glands correctly localized & $14(82 \%)$ & \\
\hline Total with 1 gland incorrectly localized & $2(12 \%)$ & 2/9 with 2-gland disease \\
\hline $\begin{array}{l}\text { Total with } 1 \text { gland not identified at all } \\
\text { Ouadrant (superior or inferior) }\end{array}$ & $1(6 \%)$ & 1/9 with 2-gland disease \\
\hline Total with all glands correctly localized & $9(53 \%)$ & $\begin{array}{l}7 / 9 \text { with } 2 \text {-gland disease } \\
1 / 3 \text { with } 3 \text {-gland disease } \\
1 / 5 \text { with } 3.5 \text {-gland disease }\end{array}$ \\
\hline Total with 1 gland incorrectly localized & $2^{\mathrm{a}}$ & $\begin{array}{l}1 / 3 \text { with } 3 \text {-gland disease } \\
1 \text { with } 3.5 \text {-gland disease also had } \\
1 \text { gland not identified and } \\
\text { counted twice }{ }^{\mathrm{a}}\end{array}$ \\
\hline Total with 1 gland not identified & $6^{\mathrm{a}}$ & $\begin{array}{l}2 / 9 \text { with } 2 \text {-gland disease } \\
1 / 3 \text { with } 3 \text {-gland disease } \\
3 / 5 \text { with } 3.5 \text {-gland disease }\end{array}$ \\
\hline Total with 2 glands not identified & 1 & 1/5 with 3.5-gland disease \\
\hline
\end{tabular}

${ }^{a}$ One also had $1 \mathrm{gland}$ incorrectly localized and counted twice.

Ozturk et $\mathrm{al}^{36}$ used $4 \mathrm{D}$-DCE at $3 \mathrm{~T}$ with precontrast and postcontrast images at 15 -second intervals for 8 timeframes with $83 \%-86 \%$ sensitivity for abnormal glands. Their postprocessing was more labor-intensive than ours with precontrast images subtracted from postcontrast images on a pixel-by-pixel basis, with glands defined by the following: 1) vivid enhancement compared with the thyroid on the first or second postcontrast images, and 2) washout on delayed images. Signal intensity was measured using ROIs drawn on consecutive images for doubtful cases. ${ }^{36}$ Another study using a limited (4-phase) dynamic postcontrast MR imaging showed a sensitivity of $80 \%$ for detection of PTAs. ${ }^{37}$

Turski et $\mathrm{al}^{38}$ used dynamic $4 \mathrm{D}$-MR imaging with incorporation of time-resolved imaging of contrast kinetics (TRICKS) angiography with a temporal resolution of 5.4 seconds, demonstrating a $64 \%$ sensitivity for detection of PTAs. ${ }^{30}$ To date, dynamic MR imaging has had better success at identifying parathyroid glands in the re-operative neck with studies at $1.5 \mathrm{~T}$ showing $90 \%{ }^{37}$ and $93 \%{ }^{39}$ of PTAs detected. The temporal resolution of this latter study, identical to ours at 6 seconds, may account for superior lesion detection, with the glands between 6 and $28 \mathrm{~mm}$ in diameter detected.

Our study showed that our described 4D-DCE MRI technique can be successfully used for accurate preoperative localization in patients with PHPT. We would like to highlight the following primary findings from our study.

Using the fast imaging tools TWIST ${ }^{23}$ and CAIPIRINHA ${ }^{14,24}$ has enabled very high spatial resolution (voxel size $=1.3 \times 1.3 \times$ $2.3 \mathrm{~mm}^{3}$ ) without sacrificing coverage or resulting in an increase in acquisition time. A large FOV $(20 \mathrm{~cm})$ from the angle of the mandible to the manubrium was scanned every 6 seconds, providing high temporal resolution and a truly dynamic interrogation exploiting the hypervascular characteristics of parathyroid glands, a characteristic that has also been targeted by $4 \mathrm{D}-\mathrm{CT}$.

The short scan time required for our technique is an advantage over conventional MR imaging, with the patient not required to hold his or her breath. The DCE images acquired at each 6-second timeframe appear as separate sequences on the PACS for analysis, allowing independent evaluation. None of our 6-second images were degraded by motion, even when the patient moved slightly between images (Fig 1). In addition to the short overall scan time of 144 seconds for our 4D-DCE MRI, our technique also has the advantage of a relatively short postprocessing time, performed without postprocessing software.

High-temporal-resolution DCE MR imaging allows differentiation of the parathyroid glands from lymph nodes and thyroid tissue due to their faster arterial enhancement and earlier contrast washout, with a mean parathyroid maximal enhancement of 13 seconds earlier than thyroid tissue and 29 seconds earlier than lymph nodes using this technique. ${ }^{21}$ At 6 seconds, our DCE temporal resolution is higher than that used by some other MR imaging authors and may account for our superior results compared with some of these other DCE MR imaging techniques. ${ }^{22}$ We have previously shown parathyroid glands to have arterial enhancement at the same time or within 1-2 timeframes (6-12 seconds) of the carotid artery and at least 2-3 timeframes (12-18 seconds) before the thyroid gland. ${ }^{21}$ This feature aids depiction of glands lying adjacent to the thyroid, those most frequently missed with 4D-CT. ${ }^{40}$

The gadolinium contrast agent for this study was MultiHance, used at the time of the study for head and neck imaging at both the University of Arizona and Icahn School of Medicine. Its relaxivity is approximately twice that of some other agents, giving excellent contrast enhancement ${ }^{41}$ and superior results for firstpass angiography compared with a macrocyclic agent. ${ }^{42}$ Because we lack experience using other agents, recommendations for alternative agents using our technique cannot be made.

Additionally, incorporation of the Dixon technique into our sequence resulted in excellent and uniform fat suppression, ${ }^{43}$ with good contrast-to-noise aiding identification of small lesions. Our high spatial resolution, combined with excellent fat saturation, enabled detection of very small parathyroid glands, with 11 MGD glands of $<0.5 \mathrm{~cm}^{3}$, an improvement over conventional T1 and $\mathrm{T} 2$ sequences, having poor detection of glands of $<0.31 \mathrm{~cm}^{3}$ and a mean size of nondetected glands of $1.4 \mathrm{~cm} .{ }^{3,31}$ Uniform fat suppression is necessary to distinguish small enhancing glands from fat but can be difficult to achieve using other techniques due to the presence of air within the lungs and upper airways and digestive tract and complex anatomy. Unlike other described dynamic techniques, TRICKS, the described protocol, does not use a subtraction methodology, avoiding degradation of images by subtraction and ghost artifacts.

Three- or 4-phase 4D-CT exposes the thyroid gland to significant radiation doses. The major advantage of $4 \mathrm{D}$-DCE MRI over $4 \mathrm{D}-\mathrm{CT}$ is the lack of exposure of the neck to the hazards of ionizing radiation, particularly for young patients whose thyroid glands are more sensitive to the carcinogenic effect of ionizing radiation, ${ }^{44}$ with the risk of differentiated thyroid cancer lasting several decades. ${ }^{45}$ This risk increases with the increased radiation 
dose. ${ }^{16} 4 \mathrm{D}$-DCE MR imaging should, therefore, be considered as an alternative to $4 \mathrm{D}$-CT for first-line investigation of PHPT in young patients requiring imaging.

Debate in the $4 \mathrm{D}-\mathrm{CT}$ literature continues regarding the relative merits of CT acquisition at 2, 2.5, or 3 or 4 time points for 30-90 seconds for optimal lesion detection, much lower than our temporal resolution, with limitations imposed by the level of radiation exposure. ${ }^{25,27,46-49}$ Although it may be tempting to lower the temporal resolution of $4 \mathrm{D}-\mathrm{DCE}$, our experience during protocol development has shown that this results in inferior gland detection and is therefore not recommended.

Our study has several limitations. First, our sample size was relatively small, which may affect the power of our analysis. Because this was a dual-institutional study without patient selection, we would expect our results to be generalizable to larger patient cohorts referred to surgeons in other institutions. Second, comparison with surgical pathology findings is not ideal, particularly for MGD, in which normal small glands may be removed or biopsied. This feature may account for the higher rate of nonidentified glands in those with higher numbers of removed glands. Additionally, some of the discrepancies in quadrant identification may be related to minor reporting differences between neuroradiologists and surgeons with regard to the anatomic location of the gland in relation to the midpole of the thyroid gland.

\section{CONCLUSIONS}

Our 4D-DCE MR imaging using the modified 4D-DCE TWIST or CAIPIRINHA technique with high spatial and temporal resolution exploits the hypervascular nature of parathyroid glands, resulting in sensitivities for gland detection of $92 \%$ and $74 \%$ for SGD and MGD, respectively, for patients undergoing primary surgery. 4D-DCE MRI has superior diagnostic accuracy compared with 4D-CT for both SGD and MGD and superior accuracy compared with unselected patients undergoing primary surgery using other dynamic MR imaging techniques. 4D-DCE MRI does not expose the neck to ionizing radiation, and it should be considered as an alternative to $4 \mathrm{D}$-CT for first-line investigation in patients with HPT, particularly young patients for whom the risk of cancer from radiation to the thyroid gland is the highest.

Disclosures: Jennifer L. Becker-UNRELATED: Consultancy: Siemens, Comments: Syngo Via consultancy.* Randall P. Owen-UNRELATED: Grants/Grants Pending: Neurovision Medical Products, Comments: grant for intraoperative video laryngoscopy.* Kambiz Nael—UNRELATED: Board Membership: Olea Medical, Comments: Medical Advisory Board. *Money paid to the institution.

\section{REFERENCES}

1. Ruda JM, Hollenbeak CS, Stack BC Jr. A systematic review of the diagnosis and treatment of primary hyperparathyroidism from 1995 to 2003. Otolaryngol Head Neck Surg 2005;132:359-72 CrossRef Medline

2. Heath H 3rd, Hodgson SF, Kennedy MA. Primary hyperparathyroidism: incidence, morbidity, and potential economic impact in a community. N Engl J Med 1980;302:189-93 CrossRef Medline

3. Ghandur-Mnaymneh L, Kimura N. The parathyroid adenoma: a histopathologic definition with a study of 172 cases of primary hyperparathyroidism. Am J Pathol 1984;115:70-83 Medline

4. Kazaure HS, Thomas S, Scheri RP, et al. The devil is in the details: assessing treatment and outcomes of 6,795 patients undergoing remedial parathyroidectomy in the Collaborative Endocrine Surgery Quality Improvement Program. Surgery 2019;165:242-49 CrossRef Medline

5. Kunstman JW, Udelsman R. Superiority of minimally invasive parathyroidectomy. Adv Surg 2012;46:171-89 CrossRef Medline

6. Beland MD, Mayo-Smith WW, Grand DJ, et al. MDCT for localization of occult parathyroid adenomas in 26 patients with primary hyperparathyroidism. AJR Am J Roentgenol 2011;196:61-65 CrossRef Medline

7. Udelsman R, Lin Z, Donovan P. The superiority of minimally invasive parathyroidectomy based on 1650 consecutive patients with primary hyperparathyroidism. Ann Surg 2011;253:585-91 CrossRef Medline

8. Harari A, Zarnegar R, Lee J, et al. Computed tomography can guide focused exploration in select patients with primary hyperparathyroidism and negative sestamibi scanning. Surgery 2008;144:970-76; discussion 976-79 CrossRef Medline

9. Smith N, Magnuson JS, Vidrine DM, et al. Minimally invasive parathyroidectomy: use of intraoperative parathyroid hormone assays after 2 preoperative localization studies. Arch Otolaryngol Head Neck Surg 2009;135:1108-11 CrossRef Medline

10. Rodgers SE, Hunter GJ, Hamberg LM, et al. Improved preoperative planning for directed parathyroidectomy with 4-dimensional computed tomography. Surgery 2006;140:932-40; discussion 940-41 CrossRef Medline

11. Hoang JK, Sung WK, Bahl M, et al. How to perform parathyroid 4D-CT: tips and traps for technique and interpretation. Radiology 2014;270:15-24 CrossRef Medline

12. Day KM, Elsayed M, Beland MD, et al. The utility of 4-dimensional computed tomography for preoperative localization of primary hyperparathyroidism in patients not localized by sestamibi or ultrasonography. Surgery 2015;157:534-39 CrossRef Medline

13. Mahajan A, Starker LF, Ghita M, et al. Parathyroid four-dimensional computed tomography: evaluation of radiation dose exposure during preoperative localization of parathyroid tumors in primary hyperparathyroidism. World J Surg 2012;36:1335-39 CrossRef Medline

14. Kelly HR, Hamberg LM, Hunter GJ. 4D-CT for preoperative localization of abnormal parathyroid glands in patients with hyperparathyroidism: accuracy and ability to stratify patients by unilateral versus bilateral disease in surgery-naive and re-exploration patients. AJNR Am J Neuroradiol 2014;35:176-81 CrossRef Medline

15. Madorin CA, Owen R, Coakley B, et al. Comparison of radiation exposure and cost between dynamic computed tomography and sestamibi scintigraphy for preoperative localization of parathyroid lesions. JAMA Surg 2013;148:500-03 CrossRef Medline

16. Ron E, Lubin JH, Shore RE, et al. Thyroid cancer after exposure to external radiation: a pooled analysis of seven studies-1995. Radiat Res 2012;178:AV43-60 CrossRef Medline

17. Kluijfhout WP, Pasternak JD, Beninato T, et al. Diagnostic performance of computed tomography for parathyroid adenoma localization; a systematic review and meta-analysis. Eur J Radiology 2017;88:117-28 CrossRef Medline

18. Griffith B, Chaudhary H, Mahmood G, et al. Accuracy of 2-phase parathyroid CT for the preoperative localization of parathyroid adenomas in primary hyperparathyroidism. AJNR Am J Neuroradiol 2015;36:2373-79 CrossRef Medline

19. Hunter GJ, Ginat DT, Kelly HR, et al. Discriminating parathyroid adenoma from local mimics by using inherent tissue attenuation and vascular information obtained with four-dimensional CT: formulation of a multinomial logistic regression model. Radiology 2014;270:168-75 CrossRef Medline

20. Ramirez AG, Shada AL, Martin AN, et al. Clinical efficacy of 2-phase versus 4-phase computed tomography for localization in primary hyperparathyroidism. Surgery 2016;160:731-37 CrossRef Medline 
21. Nael K, Hur J, Bauer A, et al. Dynamic 4D MRI for characterization of parathyroid adenomas: multiparametric analysis. AJNR Am J Neuroradiol 2015;36:2147-52 CrossRef Medline

22. Merchavy S, Luckman J, Guindy M, et al. 4D MRI for the localization of parathyroid adenoma: a novel method in evolution. Otolaryngol Head Neck Surg 2016;154:446-48 CrossRef Medline

23. Le Y, Kroeker R, Kipfer HD, et al. Development and evaluation of TWIST Dixon for dynamic contrast-enhanced (DCE) MRI with improved acquisition efficiency and fat suppression. J Magn Reson Imaging 2012;36:483-91 CrossRef Medline

24. Breuer FA, Blaimer M, Heidemann RM, et al. Controlled aliasing in parallel imaging results in higher acceleration (CAIPIRINHA) for multi-slice imaging. Magn Reson Med 2005;53:684-91 CrossRef Medline

25. Starker LF, Mahajan A, Bjorklund $\mathrm{P}$, et al. 4D parathyroid $\mathrm{CT}$ as the initial localization study for patients with de novo primary hyperparathyroidism. Ann Surg Oncol 2011;18:1723-28 CrossRef Medline

26. Lundstroem AK, Trolle W, Soerensen $\mathrm{CH}$, et al. Preoperative localization of hyperfunctioning parathyroid glands with 4D-CT. Eur Arch Otorhinolaryngol 2016;273:1253-59 CrossRef Medline

27. Chazen JL, Gupta A, Dunning A, et al. Diagnostic accuracy of 4D-CT for parathyroid adenomas and hyperplasia. AJNR Am J Neuroradiol 2012;33:429-33 CrossRef Medline

28. Bahl M, Sepahdari AR, Sosa JA, et al. Parathyroid adenomas and hyperplasia on four-dimensional CT scans: three patterns of enhancement relative to the thyroid gland justify a three-phase protocol. Radiology 2015;277:454-62 CrossRef Medline

29. Stevens SK, Chang JM, Clark OH, et al. Detection of abnormal parathyroid glands in postoperative patients with recurrent hyperparathyroidism: sensitivity of MR imaging. AJR Am J Roentgenol 1993;160:607-12 CrossRef Medline

30. Grayev AM, Gentry LR, Hartman MJ, et al. Presurgical localization of parathyroid adenomas with magnetic resonance imaging at 3.0 T: an adjunct method to supplement traditional imaging. Ann Surg Oncol 2012;19:981-89 CrossRef Medline

31. McDermott VG, Fernandez RJ, Meakem TJ, et al. Preoperative MR imaging in hyperparathyroidism: results and factors affecting parathyroid detection. AJR Am J Roentgenol 1996;166:705-10 CrossRef Medline

32. Lopez Hanninen E, Vogl TJ, Steinmuller T, et al. Preoperative contrast-enhanced MRI of the parathyroid glands in hyperparathyroidism. Invest Radiol 2000;35:426-30 CrossRef Medline

33. Ruf J, Lopez Hanninen E, Steinmuller T, et al. Preoperative localization of parathyroid glands: use of MRI, scintigraphy, and image fusion. Nuklearmedizin 2004;43:85-90 CrossRef Medline

34. Krubsack AJ, Wilson SD, Lawson TL, et al. Prospective comparison of radionuclide, computed tomographic, sonographic, and magnetic resonance localization of parathyroid tumors. Surgery 1989;106:639-44; discussion 644-46 Medline

35. Seelos KC, DeMarco R, Clark OH, et al. Persistent and recurrent hyperparathyroidism: assessment with gadopentetate dimeglumine-enhanced MR imaging. Radiology 1990;177:373-78 CrossRef Medline
36. Ozturk M, Polat AV, Celenk C, et al. The diagnostic value of $4 \mathrm{D}$ MRI at $3 \mathrm{~T}$ for the localization of parathyroid adenomas. Eur $J$ Radiol 2019;112:207-13 CrossRef Medline

37. Kluijfhout WP, Venkatesh S, Beninato T, et al. Performance of magnetic resonance imaging in the evaluation of first-time and reoperative primary hyperparathyroidism. Surgery 2016;160:747-54 CrossRef Medline

38. Turski PA, Korosec FR, Carroll TJ, et al. Contrast-enhanced magnetic resonance angiography of the carotid bifurcation using the time-resolved imaging of contrast kinetics (TRICKS) technique. Top Magn Reson Imaging 2001;12:175-81 CrossRef Medline

39. Aschenbach R, Tuda S, Lamster E, et al. Dynamic magnetic resonance angiography for localization of hyperfunctioning parathyroid glands in the reoperative neck. Eur J Radiol 2012;81:3371-77 CrossRef Medline

40. Sho S, Yuen AD, Yeh MW, et al. Factors associated with discordance between preoperative parathyroid 4-dimensional computed tomographic scans and intraoperative findings during parathyroidectomy. JAMA Surg 2017;152:1141-47 CrossRef Medline

41. Shen Y, Goerner FL, Snyder C, et al. T1 relaxivities of gadoliniumbased magnetic resonance contrast agents in human whole blood at 1.5, 3, and 7 T. Invest Radiol 2015;50:330-38 CrossRef Medline

42. Schneider G, Pasowicz M, Vymazal J, et al. Gadobenate dimeglumine and gadofosveset trisodium for MR angiography of the renal arteries: multicenter intraindividual crossover comparison. $A J R$ Am J Roentgenol 2010;195:476-85 CrossRef Medline

43. Gaddikeri S, Mossa-Basha M, Andre JB, et al. Optimal fat suppression in head and neck MRI: comparison of multipoint Dixon with 2 different fat-suppression techniques, spectral presaturation and inversion recovery, and STIR. AJNR Am J Neuroradiol 2018;39:36268 CrossRef Medline

44. Iglesias ML, Schmidt A, Ghuzlan AA, et al. Radiation exposure and thyroid cancer: a review. Arch Endocrinol Metab 2017;61:180-87 CrossRef Medline

45. Sinnott B, Ron E, Schneider AB. Exposing the thyroid to radiation: a review of its current extent, risks, and implications. Endocr Rev 2010;31:756-73 CrossRef Medline

46. Mortenson MM, Evans DB, Lee JE, et al. Parathyroid exploration in the reoperative neck: improved preoperative localization with 4Dcomputed tomography. J Am Coll Surg 2008;206:888-95; discussion 895-96 CrossRef Medline

47. Linda DD, Ng B, Rebello R, et al. The utility of multidetector computed tomography for detection of parathyroid disease in the setting of primary hyperparathyroidism. Can Assoc Radiol J 2012;63:100-08 CrossRef Medline

48. Gafton AR, Glastonbury CM, Eastwood JD, et al. Parathyroid lesions: characterization with dual-phase arterial and venous enhanced CT of the neck. AJNR Am J Neuroradiol 2012;33:949-52 CrossRef Medline

49. Noureldine SI, Aygun N, Walden MJ, et al. Multiphase computed tomography for localization of parathyroid disease in patients with primary hyperparathyroidism: how many phases do we really need? Surgery 2014;156:1300-06; discussion 13006-07 CrossRef Medline 